\title{
ANALISIS KONDISI KEUANGAN BERDASARKAN RASIO LIKUIDITAS, SOLVABILITAS DAN RENTABILITAS PADA LEMBAGA PERKREDITAN DESA (LPD) DESA PEKRAMAN BANGBANG, BANGLI
}

\author{
I Gst Bagus Wirya Gupta ${ }^{1}$ \\ Ni Wayan Dian Mariani² \\ ${ }^{1,2}$ Fakultas Ekonomi Universitas Ngurah Rai, Denpasar \\ ${ }^{2}$, e-mail : anixdianmariani@gmail.com
}

\begin{abstract}
ABSTRAK
Tujuan penelitian ini adalah untuk mengetahui kondisi keuangan LPD Desa Pekraman Bangbang ditinjau dari rasio Likuiditas, Solvabilitas dan Rentabilitas periode tahun 2012-2016. Sumber data yang digunakan adalah data primer dan sekunder. Pengumpulan data yang digunakan adalah observasi, wawancara, dan studi dokumentasi. Teknik analisis data yang digunakan adalah teknik analisis kualitatif dan kuantitatif. Hasil penelitian dikomparasikan dengan Peraturan BANK INDONESIA No.13/1/PBI/2011, menunjukkan bahwa ditinjau dari likuiditas, current ratio LPD Desa Pekraman Bangbang periode tahun 2012-2016 lebih dari 125\% namun kurang dari $149 \%$ sehingga dapat dinyatakan cukup baik. Quick ratio LPD Desa Pekraman Bangbang periode tahun 2012-2016 termasuk klasifikasi cukup baik karena berada pada posisi lebih dari $125 \%$ namun kurang dari $149 \%$ hal ini menunjukan bahwa kemampuan LPD Desa Pekraman Bangbang di tinjau dari likuiditas: curretn ratio dan quick ratio periode tahun 2012-2016 adalah cukup baik. Solvabilitas dengan analisis rasio aktiva atas hutang LPD Desa Pekraman Bangbang, dinyatakan dalam kondisi sangat baik karena berada diposisi lebih dari 10\%. Analisis rentabilitas ekonomis/return on asset (ROA) tahun 2012-2016 rentabilitas ekonomis LPD Desa Pekraman Bangbang dinyatakan dalam kondisi cukup baik. Analisis rentabilitas modal sendiri tahun 20122016 LPD Desa Bangbang dinyatakan dalam kondisi baik.
\end{abstract}

Kata Kunci : Likuiditas, Solvabilitas dan Rentabilitas

\section{ABSTRACT}

Based on this the researcher is interested to examine "Financial Condition Analysis Based on Liquidity Ratio, Solvency, and Profitability at LPD Pekraman Bangbang Village, Bangli". The formulation of this research problem is How Financial Condition LPD Pekraman Bangbang Village reviewed from the ratio of Liquidity, Solvency and Rentability period 2012-2016. Data analysis techniques used are qualitative and quantitative analysis techniques. The results of the study were compared with BANK INDONESIA Regulation No.13 / 1 / PBI / 2011, indicating that in terms of liquidity, LPD current ratio of Desa Pekraman Bangbang in the period 2012-2016 is more than $125 \%$ but less than $149 \%$ so it can be stated fairly well. The LPD Cash ratio of Quick ratio LPD Desa Pekraman Bangbang 2012-2016 period including classification is quite good because it is in the position of more than $125 \%$ but less than $149 \%$ it shows that the ability LPD Pekraman Bangbang Village in review of liquidity: curretn ratio and quick ratio period 2012 2016 is good enough. Solvency with asset ratio analysis of LPD debt of Desa Pekraman Bangbang, stated in very good condition because it is positioned more than 10\%. Analysis of economic profitability / return on asset (ROA) year 2012-2016 economic profitability LPD Pekraman Bangbang Village stated in good condition. Own rentability capital analysis in 20122016 LPD Bangbang Village stated in good condition.

Keywords: Liquidity, Solvency and Profitability 


\section{PENDAHULUAN}

Di masa era globalisasi saat ini persaingan bisnis jasa perbankan sangat pesat, hal ini ditandai dengan banyaknya muncul lembaga jasa perbankan. Hal tersebut dapat menyerap tenaga kerja dan dapat mengurangi pengangguran. Salah satu upaya masyarakat untuk membantu pemerintah dalam pembangunan nasional dan mengurangi pengangguran adalah membangun atau mendirikan suatu usaha baik itu dibidang jasa maupun dibidang dagang. Modal yang cukup besar sangat dibutuhkan dalam membangun atau mendirikan suatu usaha. Peran LPD sangatlah penting dalam peminjaman modal kepada masyarakat untuk mengembangkan usaha. Setiap perusahaan yang didirikan memiliki tujuan untuk mendapat keuntungan atau laba. Keuntungan atau laba ini, digunakan perusahaan untuk mempertahankan usahanya. Perusahaan harus selalu memperhatikan kondisi keuangannya untuk bisa mempertahankan perusahaannya tersebut.

LPD merupakan salah satu kebijakan pemerintah Daerah Bali di dalam upaya menyalurkan bantuan permodalan kepada masyarakat desa adat di Bali. Kegiatan utama LPD adalah menghimpun dana dari masyarakat berupa tabungan dan deposito, dan menyalurkan kembali kepada masyarakat yang membutuhkan dana dalam bentuk pinjaman atau kredit. Pada saat ini Lembaga Perkreditan Desa (LPD) sudah mulai berkembang dan perlu adanya peningkatan kualitas Lembaga Perkreditan Desa (LPD) terkhusus pada kondisi keuangan. Kondisi keuangan diperlukan untuk mengukur keberhasilan Lembaga

Perkreditan Desa (LPD) dalam mencapai tujuannya yaitu meningkatkan kesejahteraan serta kemampuan untuk membayar hutang, kondisi keuangan Lembaga Perkreditan Desa (LPD) dapat diketahui melalui analisis keuangan (Hendar, 2010 : 198). Analisis rasio adalah teknik yang menunjukkan hubungan antara dua unsur akunting yang memungkinkan pemilik bisnis menganalisis kinerja keuangan perusahaan (Hendar, 2010 : 199).

Peranan LPD semakin hari semakin berkembang, hal ini tidak terlepas dari kepercayaan masyarakat terhadap Lembaga Perkreditan Desa. Dalam aktivitasnya LPD memupuk modal melalui tabungan, deposito dan pinjaman dari masyarakat, selanjutnya dalam kegiatan LPD mampu memberikan pinjaman yang efektif kepada masyarakat yang membutuhkan, maka harus tercipta situasi dimana masyarakat (warga desa) merasa aman dalam menyimpan uangnya, baik dalam bentuk tabungan ataupun deposito. Agar warga desa adat merasa aman dalam menyimpan uangnya, maka diharapkan LPD tetap mampu menjaga kepercayaan masyarakat pada LPD yang bersangkutan. Kepercayaan masyarakat akan keamanan uangnya yang ditempatkan pada LPD, memegang peranan yang sangat penting, karena alasan utama dalam pemilihan tempat menabung dan mendepositokan uangnya adalah pilihan tempat yang aman. Lembaga Perkreditan Desa (LPD) tidak dapat menjalankan fungsinya apabila tidak mendapatkan kepercayaan dari masyarakat. 
Laporan keuangan adalah data yang tercermin dalam suatu laporan keuangan yang terdiri dari Neraca, Laporan Rugi Laba serta laporan diketahui kondisi dan perkembangan keuangan dari LPD dari waktu kewaktu. Laporan ini nantinya dapat dipakai untuk menyusun rencana kedepan atas kelemahan-kelemahan yang ditemui dari hasil evaluasi. . keuangan lainnya. Dengan melakukan analisis laporan keuangan dari LPD, akan dapat

Adapun kondisi keuangan pada Lembaga Perkreditan Desa (LPD) Desa Pekraman Bangbang, Bangli yang bersumber dari laporan keuangannya dari periode tahun 2012 s/d 2016 seperti terlihat pada tabel 1.1

Tabel 1.1 Perkembangan total hutang, total modal, total laba dan total aktiva di LPD Desa Pakraman Bangbang, Bangli Periode 2012-2016

\begin{tabular}{ccccccccc}
\hline tahun & $\begin{array}{c}\text { Total Hutang } \\
(\mathrm{Rp})\end{array}$ & $\%$ & $\begin{array}{c}\text { Total Modal } \\
(\mathrm{Rp})\end{array}$ & $\%$ & $\begin{array}{c}\text { Total Laba } \\
(\mathrm{Rp})\end{array}$ & $\%$ & $\begin{array}{c}\text { Total Aktiva } \\
(\mathrm{Rp})\end{array}$ & $\%$ \\
\hline 2012 & $3,942,486,572.13$ & - & $1,675,519,459.28$ & - & $325,569,525.11$ & - & $5,618,006,031.41$ & - \\
2013 & $4,580,658,440.18$ & 16 & $1,879,280,834.55$ & 12 & $333,989,185.32$ & 3 & $6,459,939,276.73$ & 15 \\
2014 & $5,940,593,645.31$ & 30 & $2,071,429,529.21$ & 10 & $352,744,358.79$ & 6 & $8,039,023,164.52$ & 24 \\
2015 & $6,912,119,214.01$ & 16 & $2,531,695,453.42$ & 22 & $574,363,677.73$ & 63 & $9,443,787,667.43$ & 17 \\
2016 & $7,610,726,598.01$ & 10 & $2,945,525,208.77$ & 16 & $643,575,226.54$ & 12 & $10,556,251,806.88$ & 12 \\
\hline
\end{tabular}

Sumber: LPD Desa Pekraman Bangbang, Bangli.

Dari tabel 1.1 dapat dilihat modal usaha dan total hutang dari periode tahun 2012 sampai 2016 selalu meningkat. Terlihat bahwa modal usaha, total hutang, dan laba usaha mengalami perubahan yang berfluktuasi, akan tetapi hal ini harus ditelusuri lebih jauh tentang bagaimana efisiensi dari modal kerja, modal kerja yang selalu meningkat belum tentu bahwa perusahaan sudah efisien menggunakan atau memanfaatkan modal kerjanya. Berdasarkan latar belakang tersebut, peneliti tertarik untuk meneliti tentang "Analisis Kondisi Keuangan Berdasarkan rasio Likuiditas, Solvabilitas dan Rentabilitas pada Lembaga Perkreditan Desa (LPD) Desa Pekraman Bangbang, Bangli”.
Analisis kondisi keuangan berpedoman pada klasifikasi PP BI No. 13/1/PBI/2011 tentang penilaian tingkat kesehatan Bank Umum dan Lembaga Perkreditan Desa (LPD).

Pokok permasalahan penelitian ini berdasarkan latar belakang masalah yang dijelaskan adalah: Bagaimana kondisi keuangan Lembaga Perkreditan Desa (LPD) Desa Pakraman Bangbang Bangli, ditinjau dari aspek Likuiditas, Solvabilitas dan Rentabilitas periode tahun 2012 sampai dengan 2016 ?

\section{METODELOGI PENELITIAN}

Penelitian ini berlokasi pada Lembaga Perkreditan Desa (LPD) Desa Pekraman Bangbang, Kecamatan Tembuku, Kabupaten 
Bangli. Objek penelitian yang menjadi objek penelitian dalam kajian ini adalah Analisis Kondisi Keuangan Berdasarkan Rasio Likuiditas, Solvabilitas dan Rentabilitas pada Lembaga Perkreditan Desa (LPD) Desa Pekraman Bangbang, Bangli. Penelitia ini menggunakan data primer dan data sekunder.

Dalam penelitiann ini menggunakan teknik analisis data

\section{HASIL DAN PEMBAHASAN Analisis Rasio Likuiditas}

Rasio ini digunakan untuk mengukur kemampuan LPD Desa Pekraman Bangbang dalam memenuhi kewajiban finansialnya (utang-utangnya) yang harus segera dibayar. Adapun hasil perhitungan

Tabel 5.5 Klasifikasi Current Ratio, Cash Ratio, dan Quick Ratio Periode Tahun $2012-2016$

\begin{tabular}{ccl}
\hline Tahun & Current Ratio $(\%)$ & Klasifikasi \\
\hline 2012 & 138,98 & Cukup Baik \\
2013 & 134,04 & Cukup Baik \\
2014 & 130,88 & Cukup Baik \\
2015 & 133,09 & Cukup Baik \\
2016 & 135,72 & Cukup Baik \\
\hline Tahun & Cash Ratio $(\%)$ & Klasifikasi \\
\hline 2012 & 62,57 & Sangat Baik \\
2013 & 61,87 & Sangat Baik \\
2014 & 46,36 & Baik \\
2015 & 38,29 & Cukup Baik \\
2016 & 42,65 & Baik \\
\hline Tahun & Quick Ratio $(\%)$ & Klasifikasi \\
\hline 2011 & 139,85 & Cukup Baik \\
2012 & 138,08 & Cukup Baik \\
2013 & 134,73 & Cukup Baik \\
2014 & 137,17 & Cukup Baik \\
2015 & 139,74 & Cukup Baik \\
\hline
\end{tabular}

Sumber : Lampiran 15 kuantitatif yaitu analisis yang didasarkan atas perhitungan dengan menggunakan rasio likuiditas, solvabilitas dan rentabilitas. Teknik analisis data kualitatif yaitu dimana dalam penelitian ini berpedoman pada klasifikasi PP BI No.12/1/PBI/2011 tentang penilaian tingkat kesehatan Bank Umum dan Lembaga Perkreditan Desa (LPD).

ratio likuiditas dan berdasarkan Peraturan Bank Indonesia Nomor: 13/1/PBI/2011 Tentang penilaian Tingkat Kesehatan Bank Umum, klasifikasi tingkat likuiditas dapat dilihat pada tabel berikut: 


\section{Current ratio}

Berdasarkan data diatas current ratio LPD Desa Pekraman Bangbang periode tahun 2012-2016 berada pada posisi cukup baik, namun setiap tahunnya selalu mengalami perubahan yang berpluktuasi yang disebabkan oleh peningkatan hutang lancar yang dikarenakan oleh peningkatan pinjaman yang diterima. Untuk meningkatkan current ratio menjadi lebih baik, sebaiknya perusahaan menaikan aktiva lancar dengan menaikan pinjaman yang diberikan dengan meningkatkan jumlah tabungan.

2.

Cash ratio

Cash ratio LPD Desa Pekraman Bangbang pada tahun 2012-2013 tergolong sangat baik, pada tahun 2014 dan 2016 tergolong klasifikasi baik. Namun pada tahun 2015 cash ratio LPD Desa Pekraman Bangbang cukup baik, penurunan cash ratio disebabkan oleh kenaikan hutang lancar disebabkan oleh peningkatan jumlah tabungan dan deposito. Untuk meningkatkan cash ratio sebaiknya perusahaan mengurangi pinjaman yang diterima sehingga kenaikan hutang lancar tidak terlalu besar dibandingkan dengan peningkatan jumlah kas yang dimiliki
3. quick ratio

Berdasarkan data tahun 2012-2016 diperoleh quick ratio lebih dari $125 \%$ sehingga LPD Desa Pekraman Bangbang berada pada klasifikasi cukup baik, namun setiap tahunnya quick ratio LPD Desa Pekraman Bangbang mengalami perubahan yang berpluktuasi yang disebabkan oleh peningkatan hutang lancar yang dikarenakan oleh peningkatan kas, bank dan piutang yang diterima. Untuk meningkatkan quick ratio menjadi lebih baik, sebaiknya perusahaan menaikan aktiva lancar dengan menaikan pinjaman yang diberikan dengan meningkatkan jumlah tabungan.

\section{Analisis Rasio Solvabilitas}

Solvabilitas adalah kemampuan perusahaan untuk membayar seluruh kewajibannya baik berupa hutang jangka pendek maupun hutang jangka panjang. Solvabilitas pada LPD Desa Pekraman Bangbang selama lima tahun dapat diketahui menggunakan tehnik analisis total assets to debt ratio dan equity to debt ratio. Berdasarkan Peraturan Bank Indonesia Nomor: 13/1/PBI/2011, klasifikasi tingkat solvabilitas dapat dilihat pada tabel berikut : 
Tabel 5.6 Tabel Perhitungan dan Interpretasi Ratio Solvabilitas LPD Desa Pekraman Bangbang Periode Tahun 2012-2016

\begin{tabular}{ccc}
\hline Tahun & Total Assets To Debt Ratio $(\%)$ & Klasifikasi \\
\hline 2012 & 142,49 & Sangat Baik \\
2013 & 141,02 & Sangat Baik \\
2014 & 135,32 & Sangat Baik \\
2015 & 136,62 & Sangat Baik \\
2016 & 138,70 & Sangat Baik \\
\hline Tahun & Equity to Debt Ratio & Klasifikasi \\
& $(\%)$ & \\
\hline 2012 & 42,49 & Sangat Baik \\
2013 & 41,02 & Sangat Baik \\
2015 & 34,86 & Sangat Baik \\
2016 & 36,62 & Sangat Baik \\
\hline
\end{tabular}

Sumber : Lampiran 1

Hasil perhitungan rasio aktiva atas hutang LPD Desa Pekraman Bangbang pada tahun 2012-2016 nilainya berfluktuasi. Rasio aktiva atas hutang rata-rata mengalami penurunan. Peningkatan rasio aktiva atas hutang terjadi pada tahun 2013. Untuk meningkatkan rasio aktiva atas hutang maka perusahaan harus meningkatkan total aktiva dengan meningkatkan pinjaman yang diberikan kepada nasabah.

1. Rasio Aktiva Atas Hutang ( Total Assets To Debt Ratio )

Berdasarkan pedoman klasifikasi yang ditetapkan dalam Peraturan Bank Indonesia Nomor: 13/1/PBI/2011 Tentang Penilaian Tingkat Kesehatan Bank Umum, klasifikasi solvabilitas LPD Desa Pekraman Bangbang dari tahun 2012-2016 total assets to debt ratio selalu menunjukkan nilai diatas 101\%, ini berarti Total assets to debt ratio LPD Desa Pekraman Bangbang termasuk klasifikasi sangat baik.
2. Rasio Modal Sendiri Atas Hutang ( Equity To Debt Ratio )

Berdasarkan hasil data penelitian yang diperoleh dari tahun 2012-2016 peningkatan rasio modal sendiri atas hutang rata-rata mengalami penurunan, peningkatan hanya terjadi di tahun 2016. Penurunan yang terjadi disebabkan oleh peningkatan total hutang yang disebabkan oleh peningkatan jumlah tabungan sukarela dan deposito nasabah. Cara untuk meningkatkan rasio modal sendiri atas hutang maka perusahaan harus meningkatkan modal sendiri dengan menambahkan modal dasar perusahaan. Klasifikasi Solvabilitas LPD Desa Pekraman Bangbang berada diatas 15\%, maka dari itu Equity to debt ratio LPD Desa Pekraman Bangbang termasuk klasifikasi sangat baik.

\section{Analisis Rasio Rentabilitas}

Rasio rentabilitas menggambarkan kemampuan perusahaan untuk menghasilkan laba selama periode tertentu. Rentabilitas LPD Desa Pekraman Bangbang 
diukur dengan menggunakan analis ROA (Return on Asset) dan Rentabilitas Modal Sendiri. Berikut hasil perhitungan dan dibandingkan dengan Peraturan Bank Indonesia

Tabel 5.8 Interpretasi Ratio Rentabilitas LPD Desa Pekraman Bangbang Periode Tahun 2012-2016

\begin{tabular}{ccl}
\hline Tahun & ROA (Return on Asset) $(\%)$ & Klasifikasi \\
\hline 2012 & 5,79 & Cukup Baik \\
2013 & 5,17 & Cukup Baik \\
2014 & 4,20 & Cukup Baik \\
2015 & 6,08 & Baik \\
2016 & 6,09 & Baik \\
\hline Tahun & Rentabilitas Modal Sendiri $(\%)$ & Klasifikasi \\
\hline 2012 & 19,43 & Baik \\
2013 & 17,77 & Baik \\
2014 & 17,02 & Baik \\
2015 & 22,68 & Sangat Baik \\
2016 & 21,84 & Sangat Baik \\
\hline
\end{tabular}

Sumber : lampiran 15

Berdasarkan data dari hasil penelitian tahun 2012-2016, dapat diketahui bahwa ROA (Return on Asset) LPD Desa Pekraman Bangbang mengalami penurunan di tahun 2013 dan 2014 meningkat lagi di tahun 2015 dan 2016. Penurunan terjadi karena peningkatan total aktiva yang disebabkan oleh peningkatan pinjaman yang diberikan, peningkatan total kas dan efek yang tidak sebanding dengan peningkatan laba. Untuk meningkatkan rentabilitas ekonomis maka perusahaan harus mengurangi biaya-biaya operasional agar lebih efisien. Rentabilitas Ekonomi ratarata menunjukan nilai $5 \%$ itu menunjukan bahwa LPD Desa Pekraman Bangbang termasuk dalam klasifikasi cukup baik.

Rentabilitas modal sendiri tahun 2015 mengalami peningkatan
Nomor: 13/1/PBI/2011, maka klasifikasi rentabilitas LPD Desa Pekraman Bangbang dapat dilihat pada tabel dibawah ini: 


\section{SIMPULAN}

Berdasarkan hasil analisis dan uraian pada bab-bab sebelumnya, kemudian dibandingkan dengan Peraturan Bank Indonesia Nomor: 13/1/PBI/2011 Tentang Penilaian Tingkat Kesehatan Bank Umum, maka dapat disimpulkan kondisi keuangan Lembaga Perkreditan Desa (LPD) Desa Pekraman Bangbang adalah sebagai berikut :

Ditinjau dari segi likuiditas dan berdasarkan pedoman klasifikasi yang ditetapkan dalam Peraturan Bank Indonesia Nomor: 13/1/PBI/2011 Tentang Penilaian Tingkat Kesehatan Bank Umum, maka current ratio dan quick ratio LPD Desa Pekraman Bangbang periode tahun 2012-2016 termasuk klasifikasi cukup baik, namun cash ratio LPD Desa Pekraman Bangbang periode tahun 2012-2016 termasuk klasifikasi baik.

Ditinjau dari segi solvabilitas dan berdasarkan pedoman klasifikasi yang ditetapkan dalam Peraturan Bank Indonesia Nomor: 13/1/PBI/2011 Tentang Penilaian Tingkat Kesehatan Bank Umum, maka Total Assets to Debt ratio dan Equity to Debt Ratio LPD Desa Pekraman Bangbang pada periode tahun 2012-2016 tergolong klasifikasi sangat baik.

Ditinjau dari segi rentabilitas yaitu rentabilitas ekonomis dan rentabilitas modal sendiri periode tahun 2012-2016 dan berdasarkan pedoman klasifikasi yang ditetapkan dalam Peraturan Bank Indonesia Nomor: 13/1/PBI/2011 Tentang Penilaian Tingkat Kesehatan Bank Umum, maka rentabilitas ekonomis LPD Desa Pekraman Bangbang tergolong klasifikasi cukup baik dan rentabilitas modal sendiri LPD Desa Pekraman Bangbang tergolong klasifikasi baik.

\section{SARAN}

Berdasarkan hasil pembahasan dan kesimpulan yang telah dikemukakan diatas, maka saran yang saya ajukan adalah sebagai berikut: hasil analisis rasio keuangan merupakan alat evaluasi dari kinerja manajemen LPD selama ini. Ditinjau dari rasio likuiditas, pada cash ratio LPD Desa Pekraman Bangbang Periode tahun 2012-2016 menunjukan kondisi keuangan yang tergolong kurang baik, maka dari itu LPD Perlu meningkatkan aktiva lancar dengan cara menaikan pinjaman atau kredit kepada nasabah dan quick rasio LPD Desa Pekraman Bangbang Periode tahun 20122016 menunjukan kondisi keuangan yang tergolong kurang baik, maka dari itu LPD perlu meningkatkan kas, bank dan piutang sehingga LPD tidak kesulitan di dalam memenuhi kewajiban finansial jangka pendek maupun hutang jangka panjang.

Selain itu hendaknya LPD Desa Pekraman Bangbang dalam meningkatkan kondisi keuangannya agar LPD memperbaiki kinerja, sehingga bisa memperbaiki kondisi keuangannya agar LPD dapat bekerja lebih efektif dan efisien. Sebagai bahan pertimbangan bagi pimpinan LPD, dalam menentukan kebijaksanaan yang menyangkut kondisi keuangan untuk masa yang akan datang, agar LPD mampu meningkatkan rasio Likuiditas dan Rentabilitas menjadi lebih baik. 


\section{REFERENSI}

Davi Ferdiansyah, 2013. Likuiditas, Solvabilitas, Aktivitas dan Rentabilitas untuk mengukur kinerja keuangan PT. Madu baru Yogyakarta tahun 2010-2012, Fakultas Ekonomi Universitas Negeri Yogyakarta.

Diana Anastasia, 2002. Akuntansi Keuangan Perusahaan Kecil, Andi, Yogyakarta.

Djarwanto PS, 2003. Pokok-pokok Analisa Laporan Keuangan, BPFE, Yogyakarta.

Hararap, Sofyan. 2007. Analisis Kritis atas Laporan Keuangan, Jakarta : PT. Raja Grafindo Persada.

Hilarius Andhika Heru Pratama, 2016. Analisis Kinerja Keuangan Berdasarkan Rasio Likuiditas, Solvabilitas dan Rentabilitas pada Koperasi Tahun 20112015. Fakultas Ekonomi Universitas Sanata Dharma Yogyakarta.

Hendar, 2010. Manajemen Perusahaan Koperasi Pokok-pokok Pikiran Mengenai Manajemen dan
Kewirauhaan. Jakarta : Penerbit Erlangga.

Hery, 2015. Analisis Laporan Keuangan Pendekatan Rasio Keuangan, CAPS, Yogyakarta.

Munawir, 2002. Analisa Laporan Keuangan, Yogyakarta : Penerbit UPP-AMP YKPN.

Munawir. 2010. Analisis Laporan Keuangan. Yogyakarta : Liberty.

Riyanto Bambang, 2001. Dasardasar Pembelajaran Perusahaan, Edisi Keempat, BPFE, Yogyakarta.

Siamat, 2005, Manajemen Keuangan, Kebijakan moneter dan Perbankan, edisi kesatu, Fakultas Ekonomi Universitas Indonesia, Jakarta.

Sugiri Slamet dan Riyono Bogat Agus, 2001. Akuntansi Pengantar 1, Edisi Keempat, Cetakan Pertama, AMP YKPN, Yogyakarta

http://www.bi.go.id/web/id

https://www.coursehero.com 